\title{
DIFERENÇAS ESTRUTURAIS ENTRE TEGUMENTOS DE SEMENTES DE SOJA COM PERMEABILIDADE CONTRASTANTE ${ }^{1}$
}

\author{
LILIANE MARCIA MERTZ² , FERNANDO AUGUSTO HENNING², HELEN LÚCIA DA CRUZ², GERI EDUARDO MENEGHELLO², \\ CIBELE DOS SANTOS FERRARI ${ }^{2}$, PAULO DEJALMA ZIMMER ${ }^{3}$.
}

\begin{abstract}
RESUMO - A exposição das sementes de soja a ciclos alternados de elevada e baixa umidades antes da colheita, provocado pela ocorrência de chuvas freqüentes, orvalho ou às flutuações diárias da umidade relativa do ar, resulta na deterioração por umidade, a qual pode ser apontada como a principal causa para a baixa qualidade das sementes. Alguns trabalhos têm evidenciado a existência de genótipos de soja contrastantes para qualidade fisiológica de sementes. Tais diferenças podem existir em virtude da total ou parcial impermeabilidade do tegumento à penetração de água, o que torna as sementes menos susceptíveis aos danos mecânicos, as adversidades climáticas e a deterioração por umidade. O objetivo desse estudo foi avaliar a qualidade fisiológica das sementes dos genótipos de soja CD-202 (tegumento amarelo, permeável e susceptível a deterioração) e TP (tegumento preto, semi-permeável e resistente a deterioração) e identificar diferenças estruturais existentes entre os tegumentos desses genótipos. Na determinação da qualidade fisiológica das sementes utilizaram-se os testes de germinação e vigor (condutividade elétrica e envelhecimento acelerado). Para avaliação da estrutura dos tegumentos, foram coletadas sementes de soja em diferentes estádios de desenvolvimento (25, 40 e 55 dias após a antese). Essas amostras foram encaminhadas ao Laboratório de Imunologia e Microscopia Eletrônica da Embrapa Clima Temperado, onde os tecidos de tegumento foram visualizados em microscópio ótico Olympus BX 51 com aumento de 40x, através de cortes histológicos na região oposta ao hilo. De acordo com os resultados do trabalho, sementes do genótipo TP apresentaram qualidade fisiológica superior em relação ao genótipo CD-202. Quanto à caracterização morfológica, foram detectadas diferenças entre as estruturas dos tegumentos de soja de coloração preta e amarela, as quais podem estar relacionadas à qualidade de sementes.
\end{abstract}

Termos para indexação: tegumento preto, tegumento amarelo, Glycine max.

\section{STRUCTURAL DIFFERENCES BETWEEN SOYBEAN SEEDS COAT WITH CONTRASTING PERMEABILITY}

\begin{abstract}
The exposition of soybean seeds to alternated cycles of high and low humidity before harvesting, due to frequent rain, dew or daily flotation of the relative humidity of the air, results in deterioration by humidity which can be pointed as the main cause for seeds low quality. Some works have made evident the existence of contrasting genotypes for seeds physiological quality. There are such differences because the presence of seeds with total or partial impermeability for water absorption by the coat that makes them less susceptible to mechanical damages, weather
\end{abstract}

${ }^{1}$ Submetido em 20/02/2008. Aceito para publicação em 21/08/2008. Parte da dissertação de Mestrado apresentada pelo primeiro autor ao Programa de Pós-Graduação em Ciência e Tecnologia de Sementes, FAEM, UFPel.

${ }^{2}$ Alunos do Programa de Pós-Graduação em Ciência e Tecnologia de
Sementes, FAEM, UFPel.

${ }^{3}$ Professor do Departamento de Fitotecnia FAEM, UFPEL. 
adversities, deterioration by humidity and pathogen occurrence. The objective of this study was to evaluate the physiological quality of seeds from genotypes CD-202 (yellow coat, permeable and susceptible to deterioration) and TP (black coat, semi-permeable and resistent to deterioration) and identify structural differences between the coats of these genotypes. The physiological quality of the seeds was obtained by germination tests and vigour (accelerated ageing and electrical conductivity). To evaluate structural differences, soybean seeds were collected at different development stages (25, 40 and 55 days after the anthesis). These samples were sent to the Laboratory of Immunology and Electronic Microscopy of Embrapa Clima Temperado, where traverse cuts in the seeds coat in ultramicrotome "Leica", with $1 \mu \mathrm{m}$ of thickness were carried out. Coats were stained with methylene blue $1 \%$ and borax 1\% and visualized in optic microscope Olympus BX 51 in increase of 40x. According to the results genotype TP presented higher physiological quality in relation to genotype CD-202. Structural differences were observed between the coats of the two genotypes which may be related to physiological quality of seeds.

Index terms: black coat, yellow coat, Glycine max.

\section{INTRODUÇÃO}

A qualidade das sementes pode ser afetada por diversos fatores durante todo o processo de produção, iniciando pelos fatores genéticos, onde diferentes variedades de uma mesma espécie podem apresentar maior ou menor vigor e longevidade, passando pelas adversidades ocorridas no desenvolvimento das sementes e após a maturidade fisiológica, que expõem as sementes ao ataque de pragas e microrganismos e finalizando com a ocorrência de danos mecânicos nos processos de colheita, beneficiamento e armazenamento. Todos estes problemas que comprometem a qualidade fisiológica das sementes podem ser relacionados às características do tegumento das sementes (Souza e Marcos-Filho, 2001).

Entre genótipos de soja existe variabilidade genética quanto à qualidade fisiológica de sementes, a qual pode ser utilizada em programas de melhoramento genético. Um exemplo é a diferença de genótipos de soja quanto à resistência ao dano mecânico e a existência de métodos capazes de provocar e avaliar tais danos. Maior tolerância aos danos mecânicos tem sido relacionada ao maior teor de lignina no tegumento da semente de soja enquanto a resistência à deterioração no campo tem sido relacionada ao grau de permeabilidade do tegumento (Alvarez, 1997).

A semi-permeabilidade do tegumento reduz as flutuações de umidade que ocorrem nas sementes devido às variações das condições de umidade no campo, tornando as sementes menos suscetíveis à deterioração. Uma menor incidência de patógenos transmitidos por sementes tem sido relatada em linhagens com tegumento semi-permeável. Outras vantagens resultantes de tal característica são maior potencial de armazenamento, maior resistência aos danos mecânicos durante a colheita, menor índice de ocorrência de danos causados por percevejos e maior tolerância à deterioração a campo, mesmo em condições extremas de estresse (França Neto et al., 2000).

No entanto, apesar de todas essas vantagens, sementes com tegumento semi-permeável não são utilizadas comercialmente, pois tratam-se de linhagens não melhoradas, com tegumento preto e que não apresentam as características que estão presentes nas cultivares modernas.

Segundo França Neto e Potts (1979), a inclusão de características relacionadas à semi-permeabilidade do tegumento, em cultivares modernas e de boas características agronômicas, pode reduzir os índices de deterioração no campo, aumentar o potencial de armazenamento da semente, diminuir os danos por microrganismos e, possivelmente, diminui os danos causados pela trilha mecânica. No entanto, ainda há necessidade de caracterizar quais são as estruturas envolvidas com o caráter.

As propriedades do tegumento da semente de soja já foi motivo de estudo para inúmeros pesquisadores (Miller et al., 1999; Souza e Marcos-Filho, 2001; Ma etal., 2004), no entanto, não se comprovou quais são as estruturas do tegumento que estão realmente associadas à permeabilidade.

Estudos através de microscopia eletrônica com corte transversal ao tegumento da semente de soja permitiram observar, que a estrutura básica do tegumento da semente dessa 
espécie é composta pela epiderme da testa, a qual é formada pela cutícula e pelas células paliçádicas ou macroesclerídeos; hipoderme da testa; e pelas células parenquimatosas (Peske e Pereira, 1983). Entretanto, não foram encontrados trabalhos que analisassem a estrutura desses tegumentos, em genótipos de soja com tegumento preto.

O objetivo desse estudo foi avaliar a qualidade fisiológica das sementes de soja dos genótipos CD-202 (tegumento amarelo, permeável e susceptível a deterioração) e TP (tegumento preto, semi-permeável e resistente a deterioração) e identificar diferenças estruturais entre os tegumentos das sementes desses genótipos.

\section{MATERIAL E MÉTODOS}

Produção do material vegetal: Foram utilizadas sementes de dois genótipos de soja contrastantes para as características de tegumento, o CD-202 (tegumento amarelo, permeável e suscetível à deterioração) e o TP (tegumento preto, semi-permeável e resistente à deterioração), fornecidas pelo programa de melhoramento da empresa COODETEC.

A semeadura foi realizada em casa-de-vegetação situada na Estação Terras Baixas do Centro de Pesquisa Agropecuária da Embrapa Clima Temperado (CPACT) Pelotas/RS, durante o ano agrícola 2005/06.

Foram utilizados baldes plásticos preenchidos com solo procedente de área de cultivo com soja, semeando-se cinco sementes por recipiente. Após a emergência realizouse raleio deixando-se duas plântulas por balde. Para cada genótipo utilizaram-se quatro repetições de oito plantas, resultando em um total de 16 baldes por genótipo.

A partir da antese iniciou-se a marcação de flores, para que todas as sementes coletadas estivessem no mesmo estádio de desenvolvimento. Para avaliação das diferenças estruturais entre os genótipos, realizaram-se coletas aos 25 , 40 e 55 dias após a antese, ao passo que para determinação da qualidade fisiológica, utilizaram-se sementes coletadas aos 70 dias após a antese.

A qualidade fisiológica das sementes foi avaliada através dos testes de germinação, condutividade elétrica e envelhecimento acelerado.

Teste de Germinação: foram utilizadas 400 sementes semeadas em rolos de papel toalha Germitest (com 25 sementes por rolo), umedecidos e colocados em germinador com temperatura constante $\left(25^{\circ} \mathrm{C}\right)$. A avaliação foi realizada no sétimo dia após a semeadura seguindo as prescrições das Regras para Análise de Sementes (Brasil, 1992), computandose apenas as plântulas normais.
Teste de Condutividade elétrica: utilizaram-se quatro sub-amostras de 25 sementes (sem presença de sementes deformadas), as quais foram pesadas e em seguida, imersas em $75 \mathrm{~mL}$ de água deionizada. As amostras foram mantidas à temperatura de $25^{\circ} \mathrm{C}$. Após período de embebição de 24 horas, foram realizadas leituras da condutividade elétrica em condutivímetro digital expressando os resultados em $\mu \mathrm{S}$.cm ${ }^{-}$ ${ }^{1} \cdot \mathrm{g}^{-1}$ (Krzyzanowski et al., 1999).

Teste de Envelhecimento acelerado: para condução do teste de envelhecimento acelerado, utilizou-se o método descrito por Krzyzanowski et al. (1999), conduzido com três repetições de 200 sementes, dispostas sobre uma bandeja de tela de arame galvanizado, fixado no interior de caixas plásticas (gerbox) as quais continham $40 \mathrm{~mL}$ de água destilada. As amostras foram incubadas em BOD, à temperatura constante de $41^{\circ} \mathrm{C}$ por 48 horas. Transcorrido esse período, as sementes foram colocadas para germinar seguindo os mesmos procedimentos utilizados no teste de germinação.

Análise estatística: utilizou-se delineamento inteira-mente casualizado para os três parâmetros avaliados (germinação, condutividade elétrica e envelhecimento acelerado). Os dados foram submetidos à análise de variância e as médias comparadas pelo teste Duncan a 5\% de significância.

Caracterização estrutural do tegumento: as diferenças estruturais entre os tegumentos dos genótipos CD-202 e TP foram avaliadas através de microscopia ótica, realizada no Laboratório de Imunologia e Microscopia Eletrônica da CPACT. Os fragmentos de tegumentos foram retirados das sementes e afixados em resina, em seguida, realizaramse cortes transversais na região oposta ao hilo, utilizando ultramicrótomo "Leica", com $1 \mu \mathrm{m}$ de espessura. O tecido vegetal foi corado com azul de metileno $1 \%$ e bórax $1 \%$, e visualizado em microscópio ótico OLYMPUS modelo BX 51, em aumento de 40x. As imagens foram digitalizadas por câmara de vídeo adaptado ao microscópio e processadas por microcomputador através do Software Image-Pró Plus. Utilizou-se um fator de conversão, multiplicando-se por 10 as medidas geradas pelo software.

\section{RESULTADOS E DISCUSSÃO}

Na Tabela 1, comparando-se a qualidade fisiológica das sementes de soja provenientes dos genótipos TP e CD - 202 observa-se que não houve diferença significativa entre os dois genótipos na avaliação do parâmetro germinação. Entretanto, o desempenho do genótipo TP foi superior 
em relação ao genótipo CD-202, quando da avaliação de vigor por meio dos testes de condutividade elétrica e envelhecimento acelerado. Isso pode ser atribuído à alta susceptibilidade do tegumento das sementes provenientes do genótipo CD - 202 a danos causados pelas flutuações na umidade, pois até mesmo nesse caso, onde as sementes foram produzidas em casa de vegetação e colhidas manualmente, o tegumento desse genótipo mostrou-se altamente frágil, com grande parte das sementes apresentando rachaduras. Esses resultados corroboram com dados obtidos por França Neto e Potts (1979), os quais constataram que sementes de soja com tegumento permeável, apresentam maior taxa de danos mecânicos quando comparadas a sementes de soja com tegumento semi-permeável. Além disso, esses pesquisadores afirmam que sementes com características de tegumento semi-permeável sofrem menos danos por umidade durante o processo de secagem. Estudos realizados por Vieira et al. (1987) em sementes de soja também evidenciaram a existência de genótipos contrastantes para a qualidade fisiológica das sementes. Segundo eles, essas diferenças podem existir em virtude da presença de sementes duras, as quais apresentam total ou parcial impermeabilidade à penetração de água no tegumento e, conseqüentemente, tornam-se menos susceptíveis aos danos mecânicos, as adversidades climáticas, a deterioração por umidade e ao ataque de patógenos.

TABELA 1. Resultados da avaliação da qualidade fisiológica de sementes de soja dos genótipos TP (Tegumento Preto) e CD - 202, produzidas em casa de vegetação, no ano agrícola 2005/06, no município de Pelotas - RS. Pelotas, UFPel - 2007.

\begin{tabular}{ccc}
\hline TESTES & Genótipo TP & Genótipo CD-202 \\
\hline Germinação $(\%)$ & $86 \mathrm{~ns}$ & 84 \\
Condutividade $\left(\mu \mathrm{S} . \mathrm{cm}^{-1} \cdot \mathrm{g}^{-1}\right)$ & $42,60 \mathrm{a}$ & $70,06 \mathrm{~b}$ \\
Envelhecimento $(\%)$ & $82 \mathrm{a}$ & $52 \mathrm{~b}$ \\
\hline
\end{tabular}

Letras que diferem na linha significam diferenças significativas pelo teste Duncan 5\% de probabilidade

Em relação à caracterização morfológica, através da microscopia eletrônica obteve-se um aumento de 40x no tamanho das imagens, permitindo visualizar de forma clara as diferenças estruturais entre os tegumentos dos genótipos TP e CD-202.

Observando-se a estrutura do tegumento das sementes de soja, nos dois genótipos estudados, pôde-se identificar a presença de três camadas: epiderme da testa, hipoderme da testa e células parenquimatosas (Figuras 1 a 6). Neste estudo não foi possível avaliar a cutícula, que é a primeira camada do tegumento. A cutícula já foi detalhadamente estudada por Ma et al. (2004) que afirmaram que a cutícula da camada paliçádica está relacionada à permeabilidade do tegumento, sendo a cutícula do tegumento permeável mecanicamente frágil, desenvolvendo rachaduras durante a embebição, enquanto que no tegumento semi-permeável seria mecanicamente forte, não sofrendo rachaduras em condições normais.

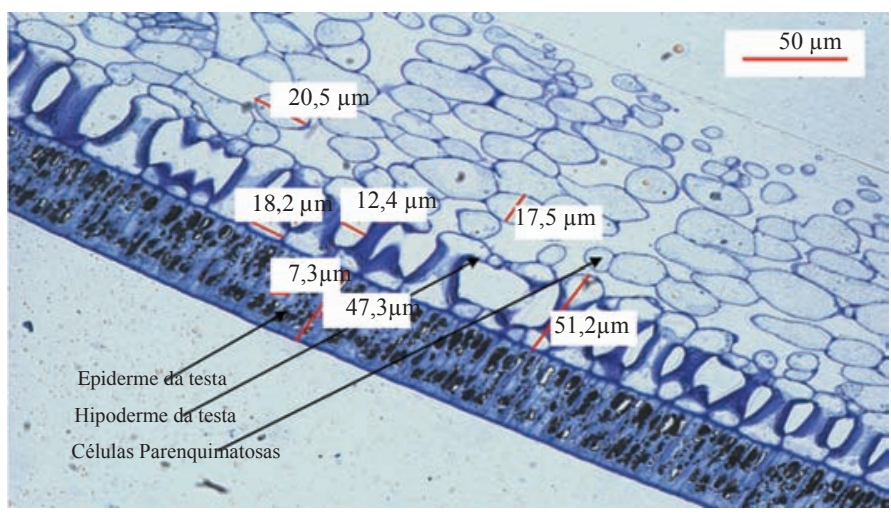

FIGURA1. Tegumento de soja do genótipo TP(Tegumento Preto), coletado 25 dias após a antese em corte transversal com ultramicrótomo, corado com azul de metileno e bórax 1\%, e visualizado em microscópio ótico, com aumento de 40x. Pelotas, UFPel - 2007.

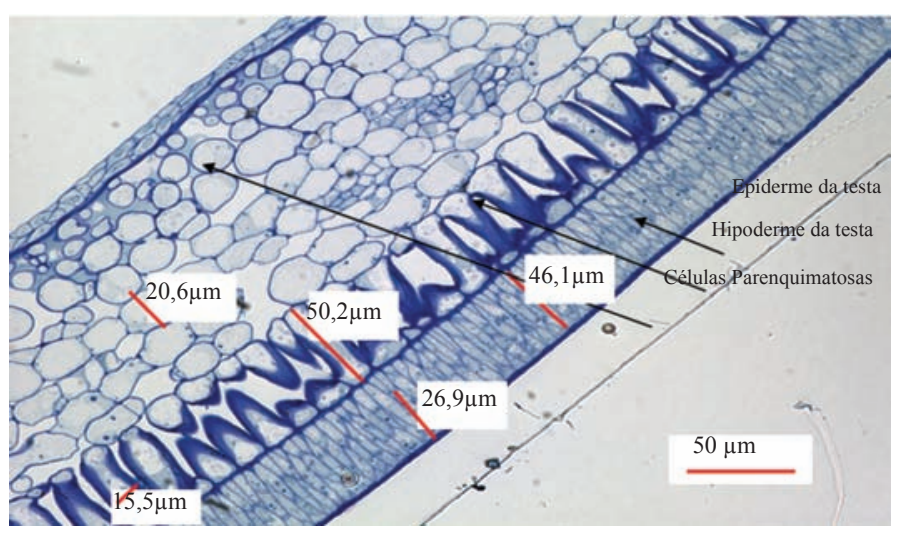

FIGURA 2.Tegumento de soja genótipo CD-202, coletado 25 dias após a antese em corte transversal com ultramicrótomo, corado com azul de metileno e bórax $1 \%$, e visualizado em microscópio ótico, com aumento de 40x. Pelotas, UFPel - 2007. 


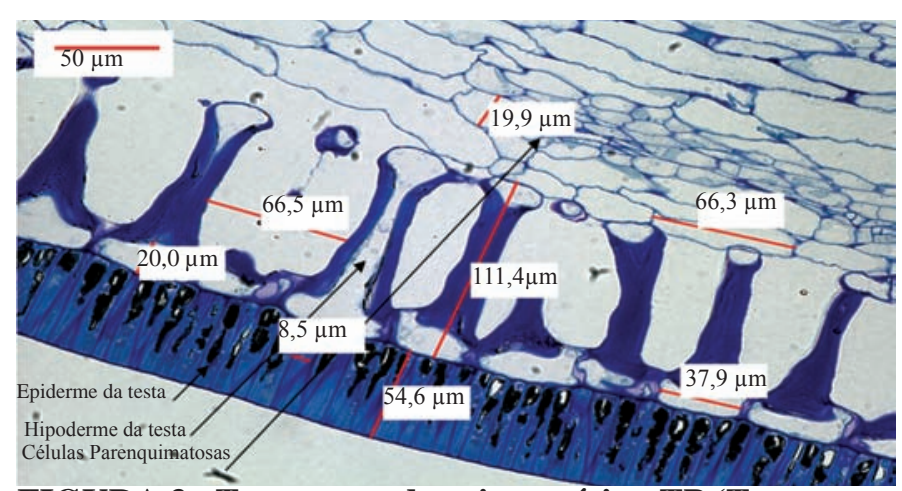

FIGURA 3 . Tegumento de soja genótipo TP (Tegumento Preto), coletado 40 dias após a antese em corte transversal com ultramicrótomo, corado com azul de metileno e bórax $1 \%$, e visualizado em microscópio ótico, com aumento de 40x. Pelotas, UFPel - 2007.

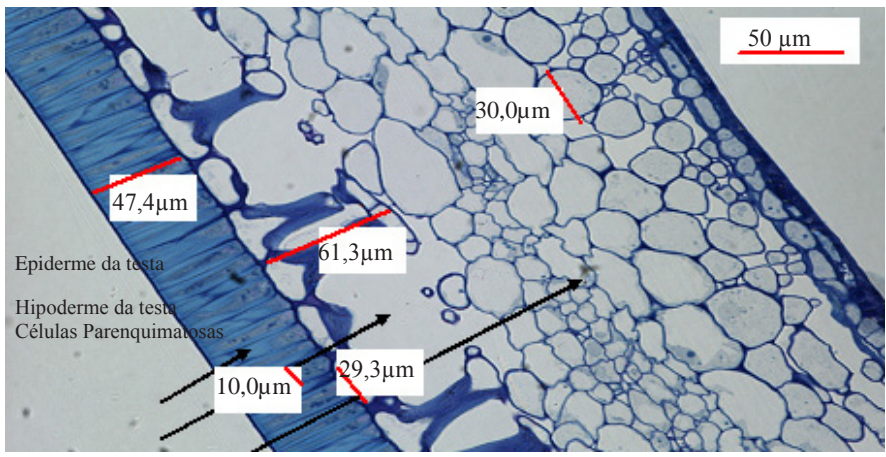

FIGURA4. Tegumento de soja genótipo CD - 202, coletado 40 dias após a antese em corte transversal com ultramicrótomo, corado com azul de metileno e bórax $1 \%$, e visualizado em microscópio ótico, com aumento de 40x. Pelotas, UFPel - 2007.

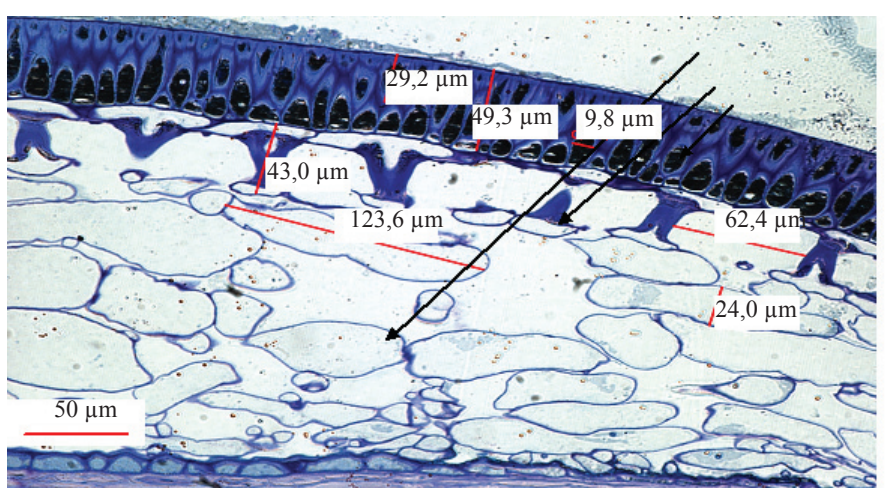

FIGURA 5 . Tegumento de soja genótipo TP (Tegumento Preto), coletado 55 dias após a antese em corte transversal com ultramicrótomo, corado com azul de metileno e bórax $1 \%$, e visualizado em microscópio ótico, com aumento de 40x. Pelotas, UFPel - 2007.

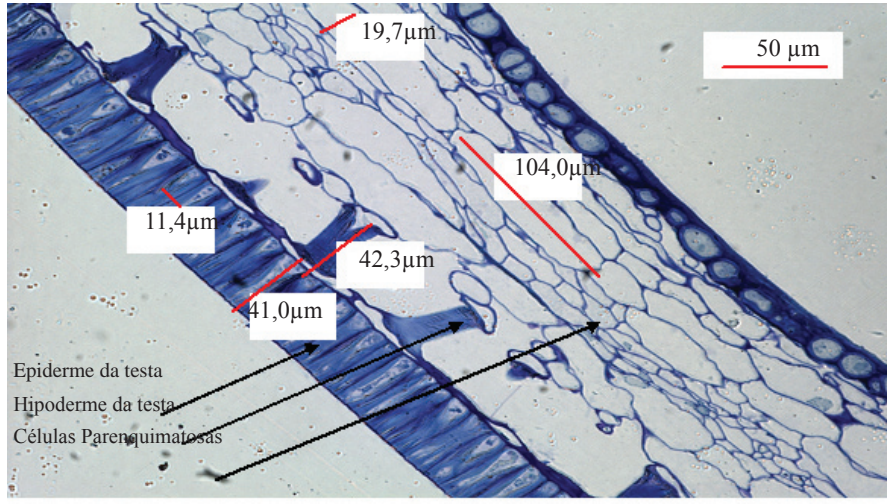

FIGURA 6. Tegumento de soja genótipo CD - 202, coletado 55 dias após a antese em corte transversal com ultramicrótomo, corado com azul de metileno e bórax $1 \%$, e visualizado em microscópio ótico com aumento de 40x. Pelotas, UFPel - 2007.

Na parte externa do tegumento encontra-se a epiderme da testa, camada formada por células paliçádicas chamadas macroesclerídeos. No genótipo TP (Figura 1), as células paliçádicas da epiderme da testa apresentam-se mais alongadas enquanto que no genótipo CD-202 (Figura 2) essas células possuem forma globulosa e justaposta. Segundo Peske e Pereira (1983), a camada paliçádica é importante para absorção de água pela semente, pois, dependendo da sua constituição química, arranjo e substâncias intercelulares, a semente pode embeber água ou não.

Ainda na Figura 1, observa-se que as células da epiderme da testa do tegumento do genótipo TP apresentaram-se com um aspecto serrilhado, enquanto que no genótipo CD - 202 (Figura2) essas células permaneceram com a estrutura lisa. Isso pode ser explicado pelo fato de que no genótipo TP, as células da epiderme da testa são altamente lignificadas (Alvarez, 1997), conferindo ao tegumento desse genótipo maior resistência aos impactos mecânicos e consequentemente ao corte provocado pelo ultramicrótomo. Já no genótipo CD - 202 as células da epiderme da testa do tegumento cederam facilmente ao corte, por serem menos estruturadas e mais frágeis aos impactos mecânicos.

Comparando-se a estrutura da epiderme da testa do genótipo TP (Figuras 1, 3 e 5) com a do genótipo CD-202 (Figuras 2, 4, e 6), observa-se que as células paliçádicas no genótipo TP apresentam alta quantidade de uma pigmentação escura. Essa coloração escura pode ser atribuída a um acúmulo de pró-antocianina ou antocianina, as quais estão presentes na epiderme da testa de sementes de soja com tegumento preto desde os estádios iniciais do desenvolvimento do 
tegumento (Todd e Vodkin, 1993). No entanto, conforme se pode observar na figura 7 , nas fases iniciais da formação da semente essa pigmentação ainda não é visível, pois as sementes de soja do genótipo TP passam a adquirir coloração escura apenas a partir dos 50 dias após a antese. Já o genótipo CD - 202, não acumula esses pigmentos e quando maduro, apresenta-se na coloração amarela (Figura 8). Segundo Asiedu e Powell (1998), a cor do tegumento das sementes é uma característica associada com a permeabilidade à água. Em estudos com algumas espécies de Fabaceas, esses mesmos autores observaram que sementes que não apresentavam acúmulo de pigmentos apresentaram maior taxa de embebição em relação às sementes pigmentadas.

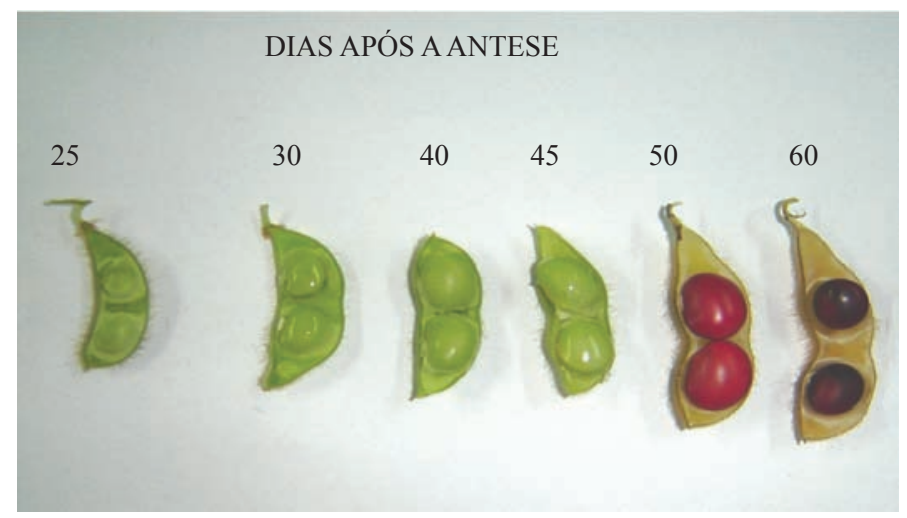

FIGURA 7. Coloração do tegumento de sementes de soja do genótipo TP em diferentes fases de desenvolvimento. Pelotas, UFPel - 2007.

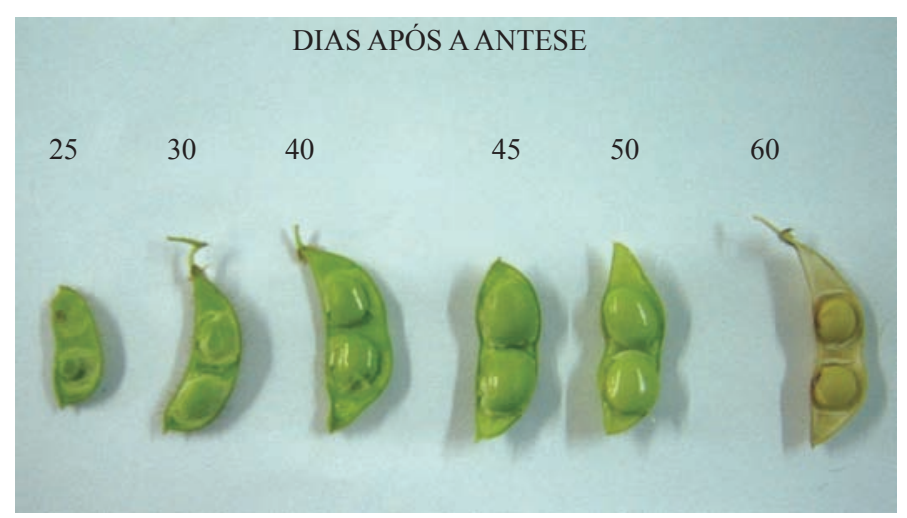

FIGURA 8. Coloração do tegumento de sementes de soja do genótipo CD - 202 em diferentes fases de desenvolvimento. Pelotas, UFPel - 2007.

Dados obtidos por Todd e Vodkin (1993) sugerem que sementes de soja com tegumento amarelo apresentam o alelo dominante do gene $I$, responsável pela coloração do tegumento. A presença desse alelo dominante inibe o acúmulo de antocianina nas paredes da epiderme da testa do tegumento amarelo. Sementes de soja com tegumento preto não possuem esse alelo dominante e, portanto, apresentam acúmulo de antocianina nas paredes da epiderme da testa. Segundo esses mesmos pesquisadores, em tegumentos pretos nos estádios iniciais de desenvolvimento, há presença de antocianinas vacuolares como cyanidin e pelargonidin. Já em tecidos de tegumentos maduros verifica-se a presença dos flavonóides cyanidin, pelargonidin e delphinidin.

Abaixo da epiderme da testa encontra-se a hipoderme da testa (Figuras 1 a 6), camada unicelular formada por osteoesclerídeos que são células esclerenquimatosas com parede celular de espessura desuniforme, as quais constituem uma camada de suporte com considerável espaço intercelular. A espessura da camada da hipoderme da testa do tegumento do genótipo TP, apresentou-se mais espessa que no tegumento do genótipo CD-202. Essa diferença foi mais evidente aos 40 dias de formação do tegumento, onde as células da hipoderme da testa do genótipo TP apresentaram em torno de $111 \mu \mathrm{m}$ (Figura 3 ) ao passo que no genótipo CD202, essa camada mediu aproximadamente $60 \mu \mathrm{m}$ (Figura 4), correspondendo a uma diferença de $45 \%$.

Avaliando-se a espessura das camadas da epiderme da testa e hipoderme da testa, observa-se que em todas as épocas avaliadas, essas camadas apresentaram-se mais espessas no genótipo TP que no genótipo CD-202. Esses resultados corroboram com trabalho realizado por Horlings et al. (1991), onde sementes de soja de genótipos com tegumento preto apresentam maior espessura do tegumento quando comparado a genótipos com tegumento amarelo. Os autores afirmam que a maior espessura do tegumento confere à semente maior resistência à deterioração no campo.

Comparando-se os tegumentos jovens, (Figuras $1 \mathrm{e}$ 2), aos 25 dias após antese com os tegumentos já maduros (Figuras 5 e 6) aos 55 dias após antese, constata-se que as camadas que compõem o tegumento das sementes de soja já estão presentes desde os 25 dias. Nos tegumentos mais maduros, aos 55 dias após a antese, observa-se que há uma diminuição na espessura das camadas da epiderme da testa e hipoderme da testa, o que pode ser atribuído a uma compressão dessas camadas provocada pelo crescimento dos cotilédones.

A terceira e última camada visualizada no tegumento das sementes de soja é uma camada formada de células parênquimatosas (Figuras 1 a 6). Estas células possuem forma mais ou menos cilíndrica e parede celular fina, formando uma estrutura com a sobreposição de 6 a 8 camadas 
de células. Nessa camada, foram observadas diferenças no formato e organização dessas células. Entretanto, não foram encontrados na bibliografia dados que afirmem existir relação dessa camada com características de resistência do tegumento.

\section{CONCLUSÕES}

Sementes de soja com tegumento preto apresentaram qualidade fisiológica superior em relação às sementes com tegumento amarelo.

Existem diferenças entre as estruturas dos tegumentos de soja de coloração preta e coloração amarela as quais podem estar relacionadas à permeabilidade do tegumento e indiretamente relacionadas à qualidade das sementes.

\section{AGRADECIMENTOS}

À CAPES, FAPERGS e CNPq pelo auxílio financeiro e à Embrapa Clima Temperado por ceder instalações para a execução do projeto.

\section{REFERÊNCIAS}

ALVAREZ, P.J.C. Relationship between soybean seed coat lignin content and resistence to mechanical damage. Seed Science and Technology, v.25, n. 2, p.209-214, 1997.

ASIEDU, E.A.; POWELL, A.A. Comparisons of storage potential of cultivar of cowpea (Vigna unguiculata) differing in seed coat pigmentation. Seed Science and Technology, v. 26, n.1, p. 211-221, 1998.

BRASIL. Ministério da Agricultura e da Reforma Agrária. Regras para análise de sementes. Brasília, DF: SNDA/ DNDV/CLAV. 1992. 365p. FRANÇA-NETO, J. B.; HENNING, A. A.; 1987.
KRZYZANOWSKI, F. C.; COSTA, N. P. Tecnologia de produção de sementes. In: A CULTURA da soja no Brasil. Londrina: EMBRAPA-CNPSo, 2000. 1 CD - ROM.

FRANÇA NETO, J.B.; POTTS, H.C. Efeitos da colheita mecânica e da secagem artificial sobre a qualidade da semente dura em soja. Revista Brasileira de Sementes, v.1, n.2, p.64-77, 1979.

HORLINGS, G.; GAMBLE, E.E.; SHANMUGASUNDARAM, S. The influence of seed size and seed coat characteristics on seed quality of soybean in the tropics: field weathering. Seed Science and Technology ,v.19, n. 3, p.665-685, 1991.

KRZYZANOWSKI, R.D.V.; VIEIRA, R.D.; FRANÇA NETO, J.B. Vigor de sementes: conceitos e testes. Londrina: ABRATES, 1999. 218p.

MA, E.; CHOLEWA, E.; MOHAMED, T.; PETERSON, C.A.; GIJZEN, M. Cracks in the palisade cuticle of soybean seed coats correlate with their permeability to water. Annals of Botany, v.44, n.2, p.213-228, 2004.

MILLER, S.S.; BOWMAN, L.A.; GIJZEN, M.; MIKI, B.L.A. Early development of the seed coat of soybean. Annals of Botany, v.84, n.3, p.297-304, 1999.

PESKE, S. T.; PEREIRA, L. A.G. Tegumento da semente de soja. Tecnologia de Sementes, v. 6, p. 23-34, 1983.

SOUZA, F. H. D.; MARCOS-FILHO, J. The seed coat as a modulator of seed-environment relationships in Fabaceae. Revista Brasileira de Botânica, v. 24, n.4. p. 365-375, 2001.

TODD, J. J.; VODKIN, L.O.; Pigmented soybean (Glycine max) seed coats accumulate proanthocyanidins during development. Plant Physiology, v. 102, p.663-670, 1993.

VIEIRA，R.D; ARANHA，L.R.S.; ATHAYDE，M.L.F.; BANZATTO, D.A. Produção, características agronômicas e qualidade fisiológica de sementes de cultivares de soja [Glycine max (L.) Merrill]. Científica, v.15, n.1, p.127-136, 